Man and World 22: 329-343, 1989.

(C) 1989 Kluwer Academic Publishers. Printed in the Netherlands.

Through the looking glass: Sartre on knowledge and the pre-reflective cogito

\title{
KATHLEEN WIDER
}

Humanities Department, University of Michigan-Dearborn, 4901 Evergreen Road, Dearborn, MI 48128

Jean-Paul Sartre, in Being and Nothingness, presents a long and complicated analysis of human consciousness. In doing so he maintains two Cartesian theses about consciousness. One is that consciousness is always self-conscious even at the level of what Sartre calls pre-reflective consciousness; for Sartre consciousness is always translucent. The second Cartesian thesis is that consciousness is infallible in terms of the beliefs it holds about its own present states. In order to defend these two theses, Sartre collapses the distinction between an act or state of consciousness and consciousness of that act or state. For Sartre consciousness of the table just is consciousness of being conscious of the table. ${ }^{1}$ On the other hand, Sartre needs to split apart consciousness even at the pre-reflective level because his distinction between the Foritself (human consciousness) and the in-itself (the rest of the world) ultimately rests on his denial that the Law of Identity applies to the For-itself. This paper will argue that he does not succeed in his attempt to hold both the Cartesian theses about consciousness discussed above and the view that consciousness is not identical to itself. The reason his attempt fails is that in order to maintain the unity of pre-reflective consciousness, he rejects an analysis of it in terms of knowledge. But in order to introduce duality into this unity, he illegitimately reintroduces knowledge at the pre-reflective level. He acknowledges this problem but dismisses it without offering a satisfactory resolution for his inconsistency.

In section one of the paper I lay out the arguments Sartre offers in the Introduction to Being and Nothingness to defend his view that the self-consciousness of the pre-reflective cogito is non-cognitive. In section two I argue that a key set of arguments Sartre uses to defend 
his claim that the Law of Identity fails to apply to the For-itself reintroduces cognitive elements into the pre-reflective cogito and is therefore inconsistent with what he has argued in the Introduction. In section three I examine how this same problem arises in Sartre's discussion of pure reflection. Finally in section four I summarize what I take to be one of the central problems in Sartre's analysis of selfconsciousness.

Sartre's defense of both Cartesian theses about consciousness rests on his collapsing of the distinction between consciousness of an object and consciousness of being conscious of an object. Sartre demands that there be a unity to consciousness even at the pre-reflective level. This unity is necessary for the translucency of consciousness, that is, for consciousness to be self-conscious even at the pre-reflective level. He spells out his argument for the self-intimating character of consciousness in the Introduction to Being and Nothingness in which he discusses pre-reflective consciousness at length. For Sartre consciousness has no contents; it is empty. There are no sense-data nor representations in consciousness (BN 11). So introspection on the model of perception would fail. There are no contents of consciousness to be perceived. The reason consciousness has introspective access to its own acts and objects is because it is its acts and objects. One should not, warns Sartre, conceive of self-consciousness at the pre-reflective level in the mode of subject/object, that is, from the point of view of knowledge (knower/known). There is no subject/object split in consciousness at the pre-reflective level. Consciousness of consciousness is not "a knowledge of knowledge" (BN 12). If self-consciousness is thought of at this level in terms of knowledge, one ends up with reflection or positional consciousness of consciousness or knowledge of consciousness. On this analysis one act of consciousness would be thought of as taking another act of consciousness as its object. According to Sartre, this would lead to either an infinite regress or to an unconscious act of consciousness (BN 12). The reason for this is because if for an act of consciousness to be pre-reflectively self-conscious, there must exist a further act of consciousness which takes the first act as its object, then, since the second act of consciousness must also be self- 
conscious, there must be a third act which takes this second act as its object. The same will be true for this third act and so on ad infinitum. On the other hand, if one attempts to stop the infinite regress at some point by denying self-consciousness to some one of the acts of consciousness in this series, then, Sartre thinks, one ends up with an unconscious act of consciousness. Either outcome is absurd. Sartre concludes that "Consciousness is not dual. If you wish to avoid an infinite regress, there must be an immediate, non-cognitive relation of the self to itself" (BN 12, emphasis mine). This is what Sartre calls non-thetic or non-positional self-consciousness. "Every positional consciousness of an object is at the same time a non-positional consciousness of itself" (BN 13). Sartre's by now famous example of this point is the cigarette counting case. I am positionally conscious of the cigarettes and their number, but I am only non-positionally conscious of my counting the cigarettes. That is, I am explicitly aware of the cigarettes, but only implicitly or latently aware of the activity of counting. What this seems to come to for Sartre is that if asked what I were doing, I could reply "I'm counting cigarettes." In other words, if I were to reflect on what I was doing, I would be explicitly aware of my present state or activity or object of consciousness. Reflection, however, has no primacy over pre-reflective consciousness for Sartre since pre-reflective consciousness can exist without reflective consciousness. Instead pre-reflective consciousness makes reflection possible. So the Cartesian cogito, Sartre argues, is not primary since the pre-reflective cogito is the condition for it. Although Sartre rejects the Cartesian cogito (or reflective consciousness) as the starting point or foundation for knowledge, he accepts the Cartesian thesis that all consciousness is translucent, that is, self-conscious. But self-consciousness at the pre-reflective level does not involve a subject (the knower) and an object (an act or mode of consciousness). Rather consciousness of an object just is consciousness of being conscious of an object. Counting just is nonpositional consciousness of counting (BN 13).

Sartre applies this analysis of consciousness not only to consciousness of objects (tables, for example) but also to affective states such as intentions, pleasures and griefs. These, for Sartre, are not things in consciousness but modes of consciousness. As such, they are selfconscious. "An intention, a pleasure, a grief can exist only as immediate self-consciousness" (BN 14). But this self-consciousness is not a new consciousness. Sartre gives an extended analysis of pleasure as a mode 
of consciousness. A pleasure just is consciousness of a pleasure. Not in the sense that there are two modes of consciousness: (1) a pleasure and (2) a consciousness of pleasure as a separate consciousness. Rather pleasure and consciousness of pleasure are logically indistinguishable. Sartre does not want "conscious" to be a quality of pleasure as "red" is a quality of the blotter, because then there could be one without the other. Just as there could be a blotter which lacks the quality of redness, so too if "conscious" were a quality of pleasure, then there could be pleasure without that quality, that is, unconscious pleasure. Then pleasure and consciousness of pleasure would be logically - even if never in fact - distinct from each other. But for Sartre consciousness is nothing but its objects and states. Likewise, just as self-consciousness is not a quality of pleasure, so pleasure is not a quality of selfconsciousness. There is not first pleasure which then becomes conscious nor consciousness which becomes pleasure.

There is no more first a consciousness which receives subsequently the affect "pleasure" like water which one stains, than there is first a pleasure (unconscious or psychological) which receives subsequently the quality of "conscious" like a pencil of light rays. (BN 15)

A pleasure and consciousness of that pleasure are indivisible for Sartre.

At the end of this discussion of the pre-reflective cogito in the Introduction of Being and Nothingness, Sartre notes that his point was to refute the Cartesian view that favors the primacy of knowledge and he wishes to argue instead for the primacy of the being of the knower. Consciousness is not, at the pre-reflective level, related to its experiences as knower to known. Consciousness is not related to its experiences at all; it is its experiences. It is nothing in itself (BN 17). He rejects the Cartesian view of consciousness as a substance although he maintains the Cartesian thesis about the self-intimating character of consciousness. The reason he can do this is because he collapses the distinction between an act or mode of consciousness and consciousness of that act or mode. 


\section{II}

$A$.

Sartre returns to a discussion of the pre-reflective cogito in chapter two of Part one of Being and Nothingness. In this section Sartre is concerned with bad faith. After examining the phenomenon of bad faith at some length, he begins to explore the conditions that allow for the possibility of bad faith. He argues that

The condition of the possibility of bad faith is that human reality, in its most immediate being, in the intra-structure of the pre-reflective cogito, must be what it is not and not be what it is. (BN 112)

My concern here is not with explicating Sartre's analysis of bad faith. My focus is rather on his analysis of belief in this section and his argument that the Law of Identity does not apply to belief. Belief or faith is central to an analysis of both bad and good faith. And Sartre finds that belief as a mode of consciousness is both itself and not itself. There is an inner disintegration of one's being involved in both bad and good faith. The reason for this is that belief even as a mode of pre-reflective consciousness is not what it is. Somehow a split occurs within the being of consciousness itself; in this case its being as belief. This is because belief as a mode of consciousness is self-conscious. That is, belief is consciousness of belief. Here Sartre applies the Cartesian doctrine of self-intimation to belief. But a problem arises given the way he unravels this application. He uses for an example of belief my believing that Pierre feels friendship for me. "If I believe that my friend Pierre likes me, this means that his friendship appears to me as the meaning of all his acts. Belief is a particular consciousness of the meaning of Pierre's acts" (BN 114). In this case belief points outward toward Pierre and his acts. However, "if I know that I believe, the belief appears to me as pure subjective determination without external correlative" (BN 114, emphasis mine). But since pre-reflective consciousness is selfconscious, then belief and consciousness of belief must be one and the same. Yet Sartre wants to introduce a split here; but to do so he reintroduces knowledge into the self-consciousness of pre-reflective consciousness. 
To believe is to know that one believes, and to know that one believes is no longer to believe. Thus to believe is not to believe any longer because that is only to believe - this is the unity of one and the same non-thetic consciousness. (BN 114, emphasis mine)

He wants to claim that belief is and is not what it is. Belief is belief but because it is self-conscious it is not belief. Once I know that I believe somehow I see it as purely subjective and so my belief is undermined; it is no longer directed outward toward its object. But Sartre has here introduced considerations of knowledge. In the introduction, however, we have seen that he clearly rejects an analysis of the selfconsciousness of pre-reflective consciousness in terms of knowledge. He acknowledges that he has "forced the description of the phenomenon [of belief] by designating it with the word to know; non-thetic consciousness is not to know" (BN 114). Yet he dismisses this inconsistency on his part by repeating his claim that pre-reflective consciousness in its translucency is at the origin of all knowledge. From that fact alone he concludes that "thus the non-thetic consciousness (of) believing is destructive of belief" (BN 114). ${ }^{2}$ His argument here seems to amount to the following: Since pre-reflective consciousness is the origin of knowledge, knowledge is involved in the self-consciousness of pre-reflective consciousness; so pre-reflective consciousness is somehow fractured within itself. But this argument won't work, for the very reasons Sartre has given in his Introduction. It does not follow that because the pre-reflective cogito is primary and underlies knowledge that it is a knowing consciousness in terms of itself. Pre-reflective consciousness does not know itself, although it is self-conscious. What self-consciousness comes to at this level, at least according to the extended analysis Sartre has given us earlier, is that if consciousness reflects upon itself it will then become explicitly aware that it is consciousness of a table or of cigarettes, for example. Prior to reflection, however, considerations of knowledge do not arise. For the Sartre of the Introduction, pre-reflective consciousness is non-cognitive. And yet it is the introduction of knowledge into the translucency of the prereflective cogito which underlies, at least in this section, his argument that "to believe is not to believe" (BN 114). 
$B$.

Immediately after his discussion of bad faith and belief, Sartre returns to an analysis of non-thetic self-consciousness. In the first section of chapter one in part two of Being and Nothingness which deals with the immediate structures of the For-itself, he argues again that the Law of Identity does not apply to consciousness even at the level of the prereflective cogito. He supports this by a further analysis of belief and argues that since consciousness even at the pre-reflective level is selfconscious, then belief because it is consciousness (of) belief is not identical to itself. He offers an argument to support this claim that is similar to the one he offered in the section on bad faith. Since the prereflective cogito is a necessary condition for reflection then it must share its structure. Since reflection alters that which is reflected upon, the self-consciousness of the pre-reflective cogito must also alter its being and duality is introduced into consciousness even at the prereflective level (BN 121). Since reflective consciousness exists for itself as a witness, pre-reflective consciousness must somehow exist as a witness to itself as well and "thus by the sole fact that my belief is apprehended as belief, it is no longer only belief; that is, it is already no longer belief, it is troubled belief" (BN 121). For Sartre, consciousness (of) belief irreparably alters belief. But that can only be so if belief could exist without consciousness (of) belief, that is, without self-awareness as one of its properties. But that is impossible on Sartre's view. Consciousness even at the pre-reflective level must be self-conscious. Belief is not belief; it is consciousness (of) belief. Although he acknowledges that since it is part of the very being of belief that it be self-conscious, that it "can exist only as troubled," he still concludes that it "exists from the start as escaping itself" (BN 122). But if from the start what it is is self-conscious, then how does it escape what it is by the results of its self-consciousness? His collapsing of the distinction between belief and consciousness (of) belief at the pre-reflective level undermines his attempt to pry them apart again at this same level.

Sartre moves to block what he sees as another attempt to reintroduce identity into pre-reflective consciousness. Against those who would hold that consciousness (of) belief is identical to consciousness (of) belief he reasserts his argument from the Introduction that consciousness (of) belief cannot be distinct from belief or one becomes 
involved in an infinite regress of acts of consciousness (BN 121). If consciousness (of) belief is an act of consciousness separate from belief, then there must be a third act of consciousness which would be consciousness (of) ((consciousness (of) belief)). That is, if to say that prereflective consciousness as belief is self-conscious means that there is an act of consciousness which takes belief as its object, then for that second act to be self-conscious, there must be a third act which takes the second act as its object and so on to infinity. Sartre thinks that if you take consciousness (of) belief to be identical to itself that you must also maintain that it is separate from belief and so become involved in this regress.

Sartre concludes after these arguments that belief is not belief and consciousness (of) belief is not consciousness (of) belief. Rather belief is consciousness (of) belief. That is, belief as a mode of consciousness is self-conscious. I must admit I still fail to see how it follows from the fact that self-awareness is a property of pre-reflective consciousness (BN 121) that an act of consciousness at the pre-reflective level, such as belief, is not itself. It does not follow from the claim that belief is belief that it is not self-conscious. Just as it would not follow from the claim that water is water that it is not fluid. Likewise an infinite regress would not follow from the claim that consciousness (of) belief is consciousness (of) belief unless one removes the parentheses and moves to the level of reflective consciousness. But if one does not take selfconsciousness at the pre-reflective level to involve consciousness taking itself as an object, then the regress does not begin. Self-aware belief just is self-aware belief. What worries Sartre, of course, is that his distinction between the For-itself and the In-itself rests on the fact that the For-itself is not what it is while the In-itself is what it is. The Foritself is not identical to itself. It is Sartre's analysis of being in the first part of Being and Nothingness which brings him to this claim. What follows is a very brief summary of that analysis. Sartre first raises the question of being and then sees that to be able to question is a human attitude and that questions can have negative as well as positive answers. So one could not ask a question especially with regard to being unless negation existed. Negation is possible only because of non-being. But you cannot derive non-being from being in itself and yet it cannot come from itself since it is non-being. So the only origin of non-being, nothingness, must be a being which is its own nothingness, that is, the For-itself. At least part of what Sartre means when he claims that the 
For-itself is a being that is its own nothingness is that the For-itself is self-conscious. That is why he needs to show that self-consciousness introduces non-being into consciousness. One way he does this is to argue that the Law of Identity fails to apply to the For-itself. However, the arguments he puts forth in this section to support this claim are weak. In the next section of this paper, I want to look carefully at his analysis of self-consciousness at the pre-reflective level which he offers immediately after this discussion of belief.

C.

A central concept in Sartre's analysis of the self-consciousness of the pre-reflective cogito is presence. ${ }^{3}$ Sartre argues that consciousness is present to itself even at the pre-reflective level. There are two ways to interpret this thesis, however. I will call these two ways the weak and strong versions of the thesis. Given the weak version of the thesis that pre-reflective consciousness is present to itself, the thesis coincides with his discussion of the self-consciousness of the pre-reflective cogito presented in the Introduction to Being and Nothingness. However, given the strong version of the thesis, Sartre is guilty of once more introducing considerations of knowledge at the pre-reflective level. But Sartre needs to put forth the strong version of the thesis in order to defend his claim that duality enters into the unity of the pre-reflective cogito and so the Law of Identity fails to apply to the For-itself even at the most primary level of consciousness. In doing so he relies on a notion of presence that he utilizes later in Being and Nothingness in his discussion of knowledge.

Sartre argues that since consciousness (of) self at the pre-reflective level is the foundation for self-consciousness and self-knowledge at the reflective level, consciousness must be present to itself from the beginning. The weak version of the claim that consciousness is present to itself even on the pre-reflective level would amount to a restatement of the claim Sartre put forward in the Introduction. That is the claim that consciousness of an object just is consciousness of being conscious of an object. That is why when asked what one is thinking or doing, one can answer. On this view one is implicitly present to one's acts of consciousness and can become explicitly present through reflection. However, on this version the unity of pre-reflective consciousness 
would remain undisturbed. Presence to oneself would follow from the fact that being conscious of an object is the same as being conscious of being conscious of an object. But Sartre wants to argue once again that there is a duality, a fracturing, within the pre-reflective cogito. To do so he introduces a notion of presence that is spelled out most clearly in the section on Transcendence which deals with the nature of knowledge. Knowledge, Sartre argues in this section, is the presence of consciousness to things (BN 240) and presence involves negation.

Non-being is an essential structure of presence. Presence encloses a radical negation as presence to that which one is not. What is present to me is what is not me. (BN 241)

Thus to know an object requires that one not be the object. Knowledge involves negation, a separation of the knower from the known. It is this notion of presence which leads him, I think, to claim that for consciousness to be present to itself it must not be itself. "The law of the for-itself, as the ontological foundation of consciousness, is to be itself in the form of presence to itself" (BN 124). Presence involves duality and separation and so "the presence of being to itself implies a detachment on the part of being in relation to itself.... If being is present to itself, it is because it is not wholly itself" (BN 124). Sartre, of course, realizes that he must maintain the unity of pre-reflective consciousness or he will reintroduce the Cartesian subject/object duality into that level of consciousness, a duality he rejected in the Introduction. Unless Sartre maintains that belief is consciousness (of) belief, for example, the possibility arises that there could be something in consciousness of which consciousness is unaware; that is, an unconscious act of consciousness. To avoid this possibility, Sartre holds to his earlier claim that there is no distinction between an act of consciousness and consciousness of that act. ${ }^{4}$ To maintain this unity and the duality presence to oneself entails, Sartre argues that what separates consciousness from itself at the pre-reflective level is nothing. But he can't have it both ways. If we take his claim seriously that nothing separates an act of consciousness from consciousness of that act, then the distance and separation involved with the notion of presence developed in the section on knowledge does not apply. The unity remains undivided. Just as he failed to argue successfully for the lack of identity between belief and consciousness (of) belief given his analysis of the unity of pre-reflective consciousness in the Introduction, so here 
his attempt to drive a wedge between consciousness and itself at the pre-reflective level fails. ${ }^{5}$ The only way to drive such a wedge is to move to the level of reflective consciousness.

\section{III}

The problems that arise for Sartre in his attempt to introduce duality into the unity of pre-reflective consciousness arise again, although with a slightly different twist, in his discussion of pure reflection. At the level of pure reflection Sartre wishes to maintain the Cartesian thesis that introspective awareness is infallible. ${ }^{6}$ To do so, he must collapse the distinction between reflective consciousness and the consciousness it reflects upon. Yet "to the extent that reflection is knowledge" (BN 213), he must pry the two apart again. This is the problem he confronts at the beginning of the final section on the temporality of the For-itself in Part two, chapter two of Being and Nothingness. We cannot think of reflective consciousness as separate from the consciousness it reflects upon, Sartre argues, or else reflective consciousness will possess at most an image or representation of the act of consciousness reflected upon (BN 213). This would be similar to accepting a perceptual model of introspection. Just as in perception (construed on a Cartesian model) one has a representation of the object perceived, so in introspection conceived of on a perceptual model, reflective consciousness would possess only a representation of the consciousness reflected upon, a sensation of a sensation so to speak. But then the kind of scepticism and lack of certainty which haunts the Cartesian view of perception would also haunt this view of introspection as a kind of quasi-perceiving. "Reflective knowledge and in particular the cogito would lose their certainty and would obtain in exchange only a certain probability, scarcely definable" (BN 213). In order to maintain the infallibility thesis then Sartre claims that "reflection - if it is to be apodictic evidence - demands that the reflective be that which is reflected-on" (BN 213). Sartre claims that there is a bond of being between reflective consciousness and the consciousness reflected upon. The one $i$ s the other. But for there to be knowledge at the level of pure reflection, reflective consciousness must be separate from the consciousness reflected upon. So the reflective must be and not be the reflected-on. However, as Sartre begins to 
explicate his claim that there is knowledge at the level of pure reflection, he realizes he must modify the claim to maintain the unity between reflective consciousness and the consciousness reflected upon. In ordinary cases of knowledge, the knower and the object of knowledge are separate. One is not the other. "To know is to make oneself other" (BN 218). But that cannot be the case with reflective knowledge since the consciousness reflected upon just is the reflective consciousness. So Sartre says that the consciousness reflected upon is only a quasi-object for reflection since the reflected upon cannot be viewed from the outside, from a point a view, given the unity of being that exists between reflective consciousness and consciousness reflected upon. Since the two pull apart from each other but not sufficiently to actually be two, reflective knowledge cannot be ordinary knowledge. Rather, according to Sartre, it is "a lightning intuition ... everything is given at once in a sort of absolute proximity" (BN 218). Later in this same discussion Sartre weakens even further his claim that pure reflection is knowledge and claims that it is "a recognition rather than knowledge" (BN 219). It differs from ordinary knowledge in that there is no real object of knowledge in reflection but only a quasi-object since it is what it 'knows' and there are no surprises with reflective 'knowledge' again since there is no transcendent object of knowledge. Still later in the discussion he says "pure reflection is never anything but a quasi-knowledge" (BN 226). The direction of the tension in this section between Sartre's need to assert the unity within consciousness and his need to argue for its duality is the reverse of its direction in his discussion of the pre-reflective cogito. There, in order to defend his claim that there is duality even in the unity of pre-reflective consciousness, he illegitimately introduces cognitive elements into the discussion of consciousness at that level. Here, in order to reassert the unity of consciousness at the level of pure reflection, he weakens and at times abandons his claim that pure reflection is knowledge.

\section{IV}

The problem here and in the earlier discussion is that in order to defend the Cartesian doctrines of self-intimation and infallibility, Sartre collapses the distinction between states or acts of consciousness and consciousness of those states or acts. He argues for the unity of consciousness at the pre-reflective level and at the level of pure reflection. Yet 
in order to defend his claim that the Law of Identity fails to apply to the For-itself, he introduces duality into consciousness even at the prereflective level and in doing so introduces cognitive elements as well. He wants to reject the Cartesian primacy of knowledge and yet maintain the Cartesian doctrines of self-intimation and infallibility. But his attempt, at least in the set of arguments I have been examining, fails. Any attempt on his part to pull apart acts or states of consciousness from consciousness of those acts or states weakens his defense of the two Cartesian doctrines. But if he maintains the absolute unity of the two, then the distinction between the In-itself and the For-itself begins to collapse. The problem Sartre is dealing with here is the problem of self-consciousness. On the one hand, how can consciousness have the kind of intimacy it does with itself, the kind of intimacy captured by the Cartesian doctrines of self-intimation and infallibility, unless it is itself? On the other hand, how can self-consciousness be consciousness of self unless there is a distance between consciousness and self? Sartre tries to solve this enduring puzzle about self-consciousness by prying apart the act or state of consciousness from consciousness of that act or state just long enough to insert nothingness between the two before they snap together again. I think this move, though it may capture the puzzlement self-consciousness gives rise to, fails to solve the puzzle.

I have been looking only at one key set of arguments Sartre advances to defend his claim that the For-itself is not identical to itself and I claim that those arguments are inconsistent with his collapsing of the distinction between acts or states of consciousness and consciousness of those acts or states. Sartre, of course, advances many other arguments in Being and Nothingness to defend his claim that the For-itself fails to coincide with itself. His defense of this claim is at the heart of his analysis of human consciousness and the way in which it is distinct from the world. One way in which he explicates this claim about the inapplicability of the Law of Identity to the For-itself is to argue that all consciousness is self-consciousness. My contention is that the set of arguments he gives to defend this explication fails. ${ }^{7}$ Limitations of space prevent me from examining whether Sartre succeeds in the arguments he gives to support other ways of explicating this claim. 
Notes

1. Jean-Paul Sartre, Being and Nothingness, trans. Hazel E. Barnes (New York: Washington Square Press, 1966), p. 11. All future references to this work will be followed in the text by BN and the page number.

2. Sartre explains in the Introduction that he uses parentheses around de in conscience de soi because in speaking of self-consciousness at the pre-reflective level he does not want the expression de soi to indicate knowledge. At the prereflective level consciousness does not take itself (i.e., its acts or modes) as an object. Yet in this discussion of belief he talks of knowing that one believes at the pre-reflective level and yet he still uses the parentheses. This ambiguity in Sartre's analysis reappears in his discussion of knowledge at the level of pure reflection.

3. By way of introducing this discussion of the For-itself's presence to itself, Sartre discusses the use of the reflexive pronoun (in French and Latin) used in locutions such as "il s'ennuie" (BN 123). Sartre's brief discussion here is akin to more recent discussions of what has come to be known as the hehimself problem. Hector-Neri Castañeda first raised this problem in analytic philosophy in a series of articles in the late sixties and the discussion has been continued more recently by John Perry and others as well as by philosophers interested in cognitive science and AI research. Issues of self-reference are at the heart of these discussions.

4. The problem Sartre wrestles with here is reflected in a recent debate between D.M. Armstrong and Sydney Shoemaker on the nature of consciousness and introspection. Armstrong argues in Consciousness and Causality (Oxford, England: Basil Blackwell, 1984) that we should conceive of the introspective awareness that each person has of her own mind on the model of perception. Just as a person can become aware of objects in the world and the states and locations of those objects through perception, so she can become aware of the acts and states of her own mind through a kind of inner perception. This view of introspection rests on a distinction which Armstrong defends most clearly in $A$ Materialist Theory of the Mind (London: Routledge \& Kegan Paul, 1968). It is a distinction he draws between a state of consciousness and awareness of that state. For Armstrong, pain and awareness of pain, e.g., are, in his own words, "distinct existences." He maintains that the "awareness (perception) of inner mental states by the person whose states they are ... is simply a further mental state, a state 'directed' towards the original inner state" (p. 94). What follows from his 'distinct existences' theory is a rejection of the two Cartesian theses Sartre accepts. In "Introspection and the Self," Midwest Studies in Philosophy, vol. x, ed. Peter A. Finch, Theodore E. Uehling, Jr., and Howard K. Wettstein (Minneapolis: University of Minnesota Press, 1986), Shoemaker mounts a sustained attack against the perceptual model of introspection. His attack of Armstrong's view rests in part on his collapsing, as Sartre does, the distinction between an act or state of consciousness and awareness of that act or state. Shoemaker argues in the same vein in Personal Identity (Oxford, 
UK: Basil Blackwell, 1984) that the capacity for being conscious of states of consciousness within oneself, such as beliefs and desires, is inseparable from the capacity for having those states. It is of the essence of at least certain mental states that they produce self-knowledge, a knowledge which is not mediated by anything like sense impressions. For Shoemaker, as well as for Sartre, being in a mental state (at least of a certain kind for Shoemaker) and being aware of that state are not logicially independent.

5. It is the ambiguity of Sartre's analysis of the self-consciousness of pre-reflective consciousness that confuses some of his critics. Marjorie Grene, for example, in Sartre (New York: New Viewpoints, 1973) attacks Sartre's defense of the Cartesian doctrine that it is a necessary condition for consciousness that it be self-conscious. She takes non-thetic consciousness of self as something different from consciousness of an object. But for Sartre in the Introduction to Being and Nothingness consciousness of the table and consciousness of being conscious of the table are one and the same. He has collapsed the distinction between the two and so being self-conscious at the pre-reflective level does not interfere with being conscious of the world. In fact they are the same; there is only one act of consciousness. She argues against Sartre that it is consciousness' "lack of consciousness of itself, its 'ignorance' of itself if you will, that makes it conscious" (p. 120). She has separated consciousness of self from consciousness of the world at the pre-reflective level. But Sartre would reject that separation. I think, however, that it is Sartre's illegitimate introduction later in Being and Nothingness of elements of knowledge at the pre-reflective level, his introduction of duality into pre-reflective consciousness that is, that might have pushed Grene to interpret him in the way she does.

6. Sartre wants to defend this Cartesian thesis while maintaining, against Descartes, that consciousness is temporal at every level of its existence, including the level of pre-reflective consciousness and pure reflection. For Descartes what self-consciousness apprehends is a momentary, instantaneous self, a moment of consciousness. For Sartre self-consciousness apprehends an historicized self, embodying a past and directed toward a future.

7. Apart from the problems $I$ have been examining in this paper, there are further problems that arise for anyone who holds that all consciousness is self-consciousness. Split brain patients, people with multiple personalities, dreamers, those under hypnosis, sleepwalkers have all been presented as cases that stand as prima facie counter-examples to the thesis that all states of consciousness involve self-consciousness. Because of limitations of space, I cannot examine whether Sartre could handle these kinds of cases and if he could how he would do so. 